University of Wollongong

Research Online

Faculty of Engineering and Information

Faculty of Engineering and Information

Sciences - Papers: Part A

Sciences

$1-1-2015$

\title{
Micro learning adaptation in MOOC: a software as a service and a personalized learner model
}

\author{
Geng Sun \\ University of Wollongong, gs147@uowmail.edu.au \\ Tingru Cui \\ University of Wollongong, tingru@uow.edu.au \\ William Guo \\ Central Queensland University \\ Ghassan Beydoun \\ University of Wollongong, beydoun@uow.edu.au \\ Dongming $\mathrm{Xu}$ \\ University of Queensland, d.xu@business.uq.edu.au
}

See next page for additional authors

Follow this and additional works at: https://ro.uow.edu.au/eispapers

Part of the Engineering Commons, and the Science and Technology Studies Commons

Research Online is the open access institutional repository for the University of Wollongong. For further information contact the UOW Library: research-pubs@uow.edu.au 


\title{
Micro learning adaptation in MOOC: a software as a service and a personalized learner model
}

\author{
Abstract \\ Micro learning is gradually becoming a common learning mode in massive open online course learning \\ (MOOC). We illustrate a research strategy to formalize and customize micro learning resources in order to \\ meet personal demands at the real time. This smart micro learning environment can be organized by a \\ Software as a Service (SaaS) we newly designed, in which educational data mining technique is mainly \\ employed to understand learners learning behaviors and recognize learning resource features in order to \\ identify potential micro learning solutions. A learner model with regards to internal and external factors is \\ also proposed for personalization in micro MOOC learning context.

\section{Disciplines} \\ Engineering | Science and Technology Studies

\section{Publication Details} \\ Sun, G., Cui, T., Guo, W., Beydoun, G., Xu, D. \& Shen, J, "Micro learning adaptation in MOOC: a software as a \\ service and a personalized learner model," Lecture Notes in Computer Science, vol. 9412, pp. 174-184, \\ 2015.
}

\section{Authors}

Geng Sun, Tingru Cui, William Guo, Ghassan Beydoun, Dongming Xu, and Jun Shen 


\title{
Micro Learning Adaptation in MOOC: a Software as a Service and a Personalized Learner Model
}

\author{
Geng Sun ${ }^{1}$, Tingru Cui ${ }^{1}$, William Guo ${ }^{2}$, Ghassan Beydoun ${ }^{1}$, Dongming Xu ${ }^{3}$, Jun Shen ${ }^{1}$ \\ 1. School of Information Systems and Technology, University of Wollongong, Australia \\ 2. School of Engineering and Technology, Central Queensland University, Australia \\ 3. UQ Business School, the University of Queensland, Australia
}

\begin{abstract}
Micro learning is gradually becoming a common learning mode in massive open online course learning (MOOC). We illustrate a research strategy to formalize and customize micro learning resources in order to meet personal demands at the real time. This smart micro learning environment can be organized by a Software as a Service (SaaS) we newly designed, in which educational data mining technique is mainly employed to understand learners learning behaviors and recognize learning resource features in order to identify potential micro learning solutions. A learner model with regards to internal and external factors is also proposed for personalization in micro MOOC learning context.
\end{abstract}

Keywords: MOOC, Mobile Learning, Micro Learning, Learner Model

\section{Introduction}

Nowadays the quantity of available learning resources is exponentially rocketing. One of the most noticeable trends in that enrichment is, along with many leading universities opening up access to their courses, the massive open online course (MOOC) gains its popularity in the whole higher education sector. It is an online course delivery framework targeting large-scale interactive participation and open access via the Web, which is an important supplement to the traditional distance education [1]. The explosive growth of learning resources leads to a revolution of education and learning [2]. Educational professionals have strived to explore the MOOC format as a regular pedagogical approach for m-learning, however, established studies show that learners using MOOC are currently suffering from low completion rate [3]. Most learners who enrolled in MOOC courses ended up dropping out. As research and development of MOOC are still in infancy, there are evidently many opportunities to improve MOOC courses as well as their affiliations, such as learning platforms and learning support services, to enable easier access and better experience for both providers and learners.

In this paper we introduce a research strategy which targets on supporting smart micro learning in MOOC. We attempt to use a Software as a Service (SaaS) which aims to give learners opportunities to make the best use of every fragmented piece of time so as to effectively engage in the MOOC learning. We particularly concentrate on delivering learners adaptive learning resources in small chunks that can be learnt in relatively short duration, and modelling the learner and learning context in an extensible manner with respect to the micro learning environment. 


\section{Micro Learning in MOOC}

\subsection{The Popularity of Micro Learning in Taking MOOC Courses}

MOOC providers try to promote their courses and affiliated educational products by making them available everywhere around the world. They leverage m-learning to enable learners to easily participate in learning activities regardless the restriction of time and location. However, these courses often start with a large number of learners, but many quit halfway. Arguably, this is mainly because learners fail to conduct effective time management, so that they are suffering from time consuming and conflicts with their real life responsibilities [3]. Another crucial factor is that learners deem it is not easy to find appropriate resources they want, or the chosen resources do not always meet their expectation [4]. The third reason is that the types of learners engaged in MOOC courses are more comprehensively diversified. Some MOOC learners do not have a concrete aim to complete an entire course as to get the credits, because they just want to acquire the specific knowledge they actually need. Such knowledge are often enclosed in small course units or passed on during phases going by midway of the course delivery. Therefore, once they are satisfied with the progress they have made, they are possible to quit while leaving assignments or tests unfinished [4].

From a research [5] which analyses the time lasting for young learners' attention in m-learning, the results show that when proceeding m-learning they frequently pause their learning activities and transfer their attention to another thing, so that their attention spans are often limited in 15 minutes. In addition, by analyzing 6.9 million records of video playing, edX found that the videos with a time length less than 6 minutes are more attractive, while students' engagements drop sharply after 6 minutes [6].

These can explain why m-learning in MOOC appears distinct from its traditional forms and modes in on-campus and distance education. [9]. It is found that learning activities are off and on frequently during the progress of MOOC course and many learning activities are completed within fragmented pieces of time. In other words, their learning processes become fragmented or of micro size. Hence, it is not surprising that MOOC follows the principles of micro learning to a certain extent and even MOOC is typically designed around the principles of micro learning enabling learners to go through bytes of learning in short duration [6]. For instance, some course materials have been chunked and the units ideally do not exceed 15 minutes [7].

\subsection{Definition of Micro Learning}

In literature, "micro learning" processes cover a time span from few seconds (e.g. in mobile learning) to up to 15 minutes or more. Another definition of micro learning is Web focused: 'micro learning refers to short-term learning activities on small learning units. In the contemporary mobile/web society, micro learning pertains to small pieces of knowledge based on web resources' [7]. With mobile devices, quite often learners accomplish learning missions in a short time period. According to the study [8], micro learning can be an assumption about the time needed to complete a relevant learning task. Hence, micro learning booms with the wide use of mobile devices, and it becomes 
a major learning means in mobile environment. Micro learning shares some similar specialties with mobile learning as they are both individually referable, self-contained, reusable and re-mixable [9].

Micro learning resources can be made available on-demand to facilitate just-in-time learning [10]. These small learning bytes not only aid quick assimilation but also make it possible to learn on the go, thus reducing the dependency on a fixed time slot or the need to take a large chunk of time out of one's working day [7]. As micro learning evolves, micro-content delivery with a sequence of micro interactions enables users to learn without information overload [10]. It is a key technology to ensure better learning results in terms of retention of propositional content [8].

\subsection{Research Challenges}

Fragmented learning with mobile devices requires learners' concentration and reflection. However, being on the go, it is fraught with distractions. Students often find themselves in situations with unpredictable but significant distractions. This leaves the mobile learners with a highly fragmented learning experience.

The operation of MOOC generates a huge amount of data about the learners, courses, educational institutions, networking, and technical details and so on. It could be very difficult for learners to quickly choose the preferred and suitable course chunks in a timely manner. Since the acquirable learning resources become massive, how to set and select the right and appropriate objectives, which stand out from the numerous available resources, brings a challenge for both MOOC providers and customers.

Moreover, there are studies indicating that personality and learning styles play significant roles in influencing academic achievement [11]. As learners commonly do not have sufficient expertise in customizing learning schedules for themselves, and perhaps they are not familiar with their own learning styles, there are high probabilities that they cannot access the right sets of micro content. This may affect them to achieve satisfactory learning outcomes though a lot of time might be spent. In the current situation, learning resources are generally divided and wrapped up by education providers or course lecturers. It considerably lacks flexibilities to fit every specific learner's time availability so that learner should get accommodated to the time length of course setting and manage to squeeze time to accomplish those learning activities.

\section{$3 \quad$ Micro Learning as a Service-System Framework}

In this paper, we attempt to employ design science method to overcome the above challenges so as to deliver learner customized learning resources, in the form of small chunks or fine-grained units. Optimally learners can easily complete the learning process of each unit within fragmented pieces of time. An ideal course module delivered to a learner should be limited in the time length (e.g. 15 minutes) to ensure a micro but complete learning experience. The framework of the proposed SaaS, Micro Learning as a Service (MLaaS), is shown in Fig.1.

The Learner Modelling Service aims to build a specific model for each learner, on the basis of his/her historical information and ongoing learning behavior. Learners' 
basic information about learning styles, preference and learning purposes is gathered. Based on these data collections, this service assesses the pre-knowledge level for each learner and marks up these features by a set of measurable variables. It is also provided with a function, which tracks learners' behaviors during micro learning process and ensures their models being kept up-to-date once new data are detected or generated.

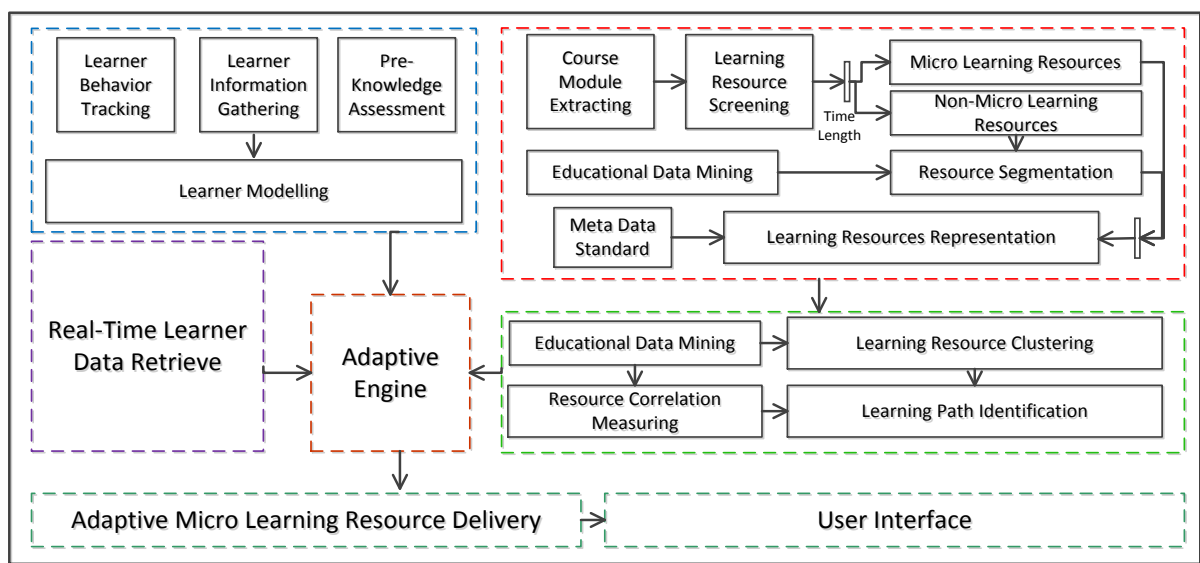

Fig. 1. Framework of Adaptive Micro Learning System for MOOC

The Learning Resource Representation Service stores all representations of the available micro learning resources. It extracts course modules from well-developed MOOC courses. Based on their time lengths, they are categorized into micro learning resources (less than 15 minutes) and non-micro learning resources. Referring to the results of EDM, these longer course modules are cut off programmatically and encapsulated into small units with reasonable time lengths. As this module holds a metadata repository, a metadata standard for describing micro course units is going to be established semantically [12]. According to this standard, all learning resources are represented in terms of discipline, key words, time length, language of instruction, popularity, difficulty and so on [12]. Data related to good-quality and mostly-followed/discussed learner-generated content, can be refilled in to Learning Resource Repository in order to support peer-to-peer learning in MOOC.

For MLaaS, the Real-Time Learner Data Retrieve Service retrieves learners' realtime data, including their learning progress and time availabilities (how many minutes they prefer to use in the moment). Furthermore, in the Learning Resource Repository Service, selected course modules are clustered using text/data mining technologies. This service also measures correlations among chunks, or, if feasible, derives correlations from existing MOOC course modules. It helps to set learning start point and exit point and it also distinguishes the suggested sequences of learning resources and identifies a learning path among them.

Taking inputs from all the above services, the Adaptive Engine acts by providing learners with customized learning resources, which are matching their current micro learning context, personal demands, learning styles and preferences. It is the core of the proposed system, which embeds machine learning technologies to realize the adaptive mechanism [13]. 


\section{$4 \quad$ Learner Modelling for Micro Learning}

Much data generated along with the proceeding of MOOC courses represents learners' behaviors in a form which is longitudinal and fine-grained. Reporting them visually and statistically in order to reveal each learner's learning story is even more crucial. This plays a significant role in conducting study ratiocination, judging learners' study status, estimating learners' study effects and carrying out learning strategy decision making. Finally, a personalized learner model for micro MOOC learning can be established by using these screened and sorted data [14], according to their historical and real-time data. This is the aim of the Learner Modelling Service. As shown in Fig. 2, the learner model consists of two domains of factors (i.e. internal and external), while the internal factors can be classified into personal intelligent and non-intelligent factors. Some components can fall in the intersection of two domains which means these components are multi-correlated to two factors. Also, a component can be overlapped with others which suggest that they are associated and mutually affected.

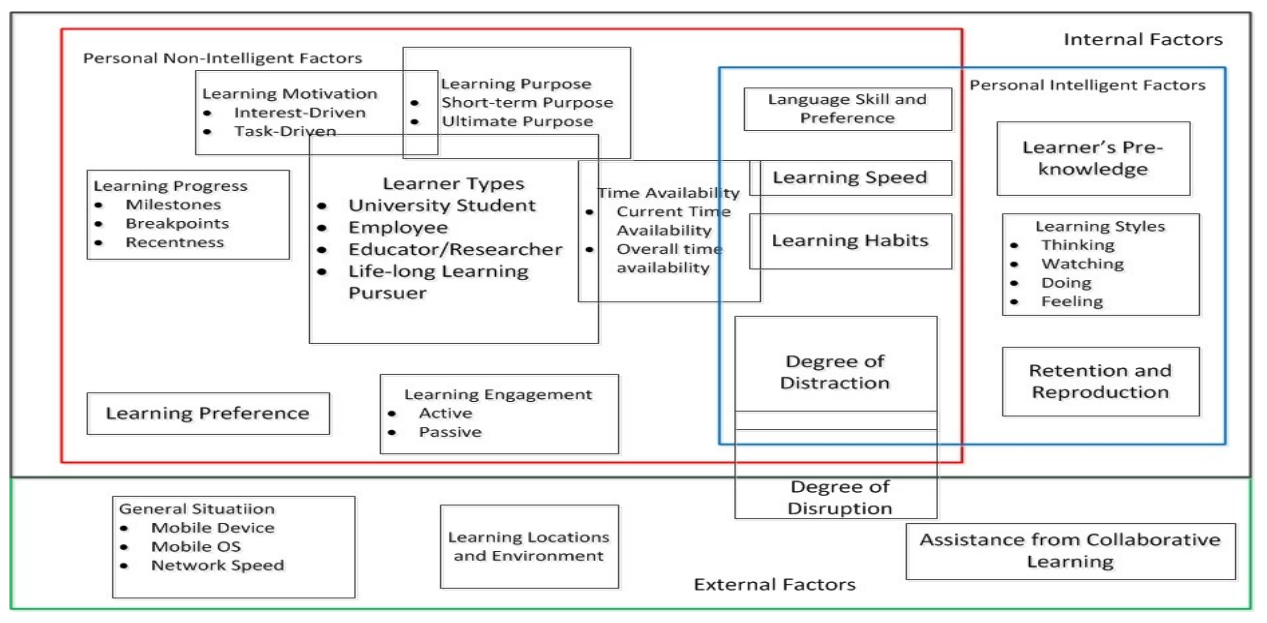

Fig. 2. Personalized Learner Model for Micro MOOC Learning

To understand the specific learning pattern of each learner from huge amount of data tracked from daily MOOC usages, EDM is the key technique we employ to explore the common shape and trend of micro learning and set the basis for subsequent adaptation mechanisms. The data collection for building learner model can be realized in two ways: mandatory request and automated extraction. The detailed learner features and learning context we intend to explore through EDM are listed as follows.

\subsection{Personal Non-Intelligent Factors}

\section{Learner Types.}

The types of MOOC learners vary evidently in accordance with their particular learning purposes and work, learning and life patterns. Their background information cannot always be searched from their registration and logon data [15]. Commonly, they can be university students, educators, researchers, employees or life-long learning pursuers. 
Time Availability.

EDM performs to clustering similar learners into a cohort. Their disposable time varies to a great extent, which is highly indicative for whether and how often these learners would adopt micro learning modes.

Their current time availability is a mandatory request for them to input before they start each micro learning activity.

\section{Learning Engagement.}

Mainly it is measured in terms of a learner's total online time length, frequency of logon, submission of required assignments, participation in forums, completion of courses or course chunks, etc.

Learners' engagement can also be categorized into active or passive learning. The former refers to that learners are self-motivated to attend virtual classes in MOOC platform so that they look for and initiatively access MOOC learning resources, which they need when they want; while the latter refers to that learners act as recipients of knowledge through information pushed by MOOC platforms or MOOC affiliated social medias, for example, they might have subscribed electronic reading materials.

\section{Progress identification.}

This is basically identified by breakpoints and milestones made by learners. In micro MOOC learning, learning activities become disperse, and the content in two continuous learning phases can be not rigidly restricted in accordance with the sequences in the course curriculum. For this reason, EDM has another significant duty to retrieve back to learners' latest learning content and activities in order to profile a learners learning recentness. Recentness is not confined into particular time points. The recentness of learning categories can be extracted automatically.

\section{Learning Motivation and Purpose.}

Basically in MOOC learning learners are either interest-driven or task-driven. Their learning purposes are identified by mandatory request data which means learner are suggested to input their learning purpose prior to the commencement of their MOOC learning.

\section{Learning Preference.}

Learning preference refers to learners' subjective and affective opinion about learning content. It can be sorted out through learners' comments and tags made on resources they have accessed.

\subsection{Personal Intelligent Factors}

\section{Learner Pre-knowledge Assessment.}

To build a profile for each learner and customize micro learning strategy for learners with different backgrounds and basis, a measure that is necessary to take in prior is to assess each learner's knowledge in terms of several standards. In micro MOOC learning, it is suggested to investigate and identify their pre-knowledge level in terms of the extent of their education, their historical courses grades in MOOC, and results of precourse quizzes which are easy to be quantized. 


\section{Learning Styles.}

Individuals differ in how they learn. Learning styles refer to the systematic differences in individuals' natural or habitual pattern of acquiring and processing information in learning situations. According to [16], learning styles can be represented as concrete experience (feeling), reflective observation (watching), abstract conceptualization (thinking) and active experimentation (doing). However, because operations on mobile devices are relatively simple, which are limited in input and output methods, these four learning styles are difficult to be reflected straightway through monitoring learners' operation. Thus, identifying learners learning style requires extra efforts, such as selfevaluation. In addition, if learning activities in other MOOC courses are specified in terms of relevant learning styles, learners' performance in an exact learning activity can indicate their value on the corresponding learning styles.

\section{Memory Ability.}

Memory ability can impact learning outcomes after the retention and reproduction stage of learning [17]. For MOOC courses in the disciplines of culture, literature, arts, language and history, etc., memory ability is one of the key measures that help learners to transfer the content of online MOOC resources into their own knowledge.

\subsection{Intersection of Non-Intelligent and Intelligent Factors}

\section{Learning Habits.}

Each individual has a completely isolated structure of available time and learning time. Learning times for on-campus instructor-led learning mostly falls in day time. Unlike that, the mobile/micro MOOC learning time spread over all 24 hours of the day. By analyzing the distribution of hotspots of frequently used learning time, EDM serve as to discover whether there are regular patterns of time organization among learners in or across cohorts, and to set up a unique learning habit summary for each learner. Their personal situations affect their learning habits, which refer to, in this paper, how learners utilize their time on MOOC learning, in what way they get learning resources passed on, how often they make pause and repetition, after how long they take a review, whether they learn several MOOC courses in parallel, during what time stages in a day they are more often to make MOOC learning happen, and among those time stages, when they are more often intending to adopt micro learning means.

\section{Learning Speed.}

This feature simply refers to the extent they have spent to go through a course chunk and finish related tasks in average, estimated from their historical learning record.

\section{Language Skill and Preference.}

Learners' language skills and preference should be taken into consideration to opt their learning resources. Because most MOOC courses are taught in English so that identification for learners' level of English skills is essential. Alternatively, this service investigates whether they prefer to learn in their native languages or second languages other than English.

\section{Degree of Distraction.}


Internally it concerns a learner's mood and emotion, and it is highly correlated to the degree of disruption which is a component of the external factors.

\subsection{External Factors}

\section{Learning Locations and Environments.}

The ways that learners get connected to Internet apparently reveal their learning locations and surrounding environments. Generally in micro learning scenarios, they are brought to Internet through wireless networks by two means, namely Wi-Fi or mobile cellular network (e.g. 4G, 3G, and GPRS). Simply, connecting to internet through mobile network means learners are taking on learning activities ad hoc, the strength changes of the mobile signals can reflect their statuses of being on-the-go. The logon data of Wi-Fi portal may also determine learners' exact indoor learning places. Normally connecting Internet via $\mathrm{Wi}$-Fi provided in public places rather than homes indicates learners are possible to experience higher frequency of interruptions as their surrounding environments can be more noisy and complicated.

\section{General Situation.}

General situation regarding learning context partially affects their learning experiences and achievements. Information regarding the mobile devices and mobile OSs the learners utilized to carry out micro MOOC learning must be specified in order to determine devices capabilities, features and limitations [18].

\section{Assistance from Collaborative Learning.}

Encouraged by the nature of how MOOC is structured and its pedagogical concept, learners can get helpful information from collaborative learning, virtual social activities over social network and content generated by other learners.

\section{Degree of Disruption.}

The degree of disruption depends on the noise and interference factors from their surroundings, conflicts with their daily works, comfortableness with the setting and layout of the MOOC platforms and course design and so on [19].

\section{Micro MOOC Learning Resources Process and Measurement}

Given some micro learning resources are provided within short time length (i.e. 15 minutes), they are normally delivered right away. However, most achievable MOOC contents are non-micro learning resources, which need to be refined properly. These contents need further processing and revision to fulfill micro learning demands. The ultimate shapes of resources after processing are summarized as follows:

- Visual encyclopedia: Learning key points are listed out in terms of the knowledge structure of the entire course. For each key point, a video or textual material is set out without time limit to clearly illustrate the contained content. Because the content contained solely cover a particular scale, accordingly the time length to go through it is short. 
- Logical segmentation of course videos: Herein each unit covers the complete information of a learning section, which includes the conditions of beginning and ending, carries coherent content, and can be studied individually.

- Course-related and educational information in affiliated social media: This is a ramification of learning resources and also rich in educational values. This resource can be found not only in forums or blogs embedded in MOOC platforms, but also in other popular social media, where learners, educators or external experts publish course-related materials [20]. A noticeable feature of this kind of resource is that its amount increases from time to time while some of the content may contain pseudoscience or incorrect information. EDM serves as to distinguish such information, which can be useless, harmful and may cause time wasted for learners. EDM can also screen well-recognized information in order to recommend to learners as their learning augmentation besides the materials from course providers [21].

- Two-way interactive contents or activity settings, ranging from feedback, assessment, review for contents generated by other learners, peer-to-peer learning, cooperative writing, collaborative work, and flipped classroom, etc...

Additionally, for learners who are usually involved in passive learning, EDM has another role to make the decision of when is the best timing to push information to learners and remind them, if needed.

For modelling purpose, a learning resource chunk is considered to be measured with regards to the following features: 1) Time length; 2) Suitability for mobile learning (inferred from frequency of historical records or instructor); 3) Shape of expression; 4) Difficulty (level of knowledge); 5) Completeness; 6) Requirement of attention; 7) Preferred learning styles; 8) one-way imparted or two-way interactive; 9) Requirement of input or hands-on practice.

\section{Conclusion and Future Work}

Building and optimizing learning path are undertaken by the Learning Resource Repository Service, and the Adaptive Engine provides a learner with proper educational resources, contents or activity settings to meet his demands and all sorts of features and context as clarified in the personalized learner model. Technical details of these two functional services are beyond the scope of this paper and we will report them in future.

In this paper we describe a research strategy which is underpinned by using adaptive micro learning as a cornerstone of the learning support SaaS. Multiple functions in the SaaS target on tailoring personalized learning schedule, specific to every fragmented time piece, for each learner. The SaaS will be finalized and implemented and implemented in the near future while we will carry out case studies focusing on finding out how our proposed system can facilitate micro learning in MOOC and how it can, qualitatively and/or quantitatively, help learners achieve their learning expectations.

\section{Reference}

1. C. King, A. Robinson and J. Vickers. 'Online Education: Targeted MOOC captivates students', Nature, vol. 505, no. 26, doi: 10.1038/505026a, 2014. 
2. J. Baggaley, 'MOOC Rampant', Distance Education, vol. 34, no. 3 pp. 368-378, 2013.

3. I. Nawrot and A. Doucet, 'Building Engagement for MOOC Students', Introducing Support for Time Management on Online Learning Platforms', Proceeding of WWW'14 Companion, 2014.

4. H. Khalil and M. Ebner, 'MOOCs Completion Rates and Possible Methods to Improve Retention - A Literature Review', Proceedings of World Conference on Educational Multimedia, Hypermedia and Telecommunications 2014.

5. G. Stockwell, 'Investigating Learner Preparedness for and Usage Patterns of Mobile Learning', ReCALL Journal of Cambridge University, vol. 20, no. 3, pp. 253-270, 2008.

6. P.J. Guo, J. Kim and R. Rubin, 'How Video Production Affects Student Engagement: An Empirical Study of MOOC Videos', The 1st ACM Conference on Learning at Scale (L@S), Atlanta, Georgia, US, 2014

7. D. Kovachev, Y. Cao, R. Klamma and M. Jarke, 'Learn-as-you-go, New Ways of Cloud Based Micro-learning for the Mobile Web', 10th International Conference on Web-based Learning, Hongkong, December 2011.

8. P.A.Bruck, L.Motiwalla and F. Foerster, 'Mobile Learning with Micro-content: A Framework and Evaluation', Proceeding of BLED, 2012, http://aisel.aisnet.org/bled2012/2.

9. T. Hug and M. Lindner, 'ML: Emerging Concepts, Practices and Technologies after eLearning', Proceedings of micro learning 2005, Austria, June 2005

10. M. I. Souza and S. F. D. Amaral, 'Educational Microcontent for Mobile Learning Virtual Environments', Creative Education, vol. 5, pp. 672-681, 2014.

11. G. Sun and J. Shen, 'Facilitating Social Collaboration in Mobile Cloud-Based Learning: A Teamwork as a Service (TaaS) Approach', IEEE Transactions on Learning Technologies, vol. 7, no. 3, pp. 207-220, 2014.

12. G. Beydoun, 'Formal Concept Analysis for an e-learning Semantic Web', Expert Systems with Applications, vol. 36, no.8, pp. 10952-10961, 2009.

13. A. Al-Hmouz, A, J. Shen, R. Al-Hmouz and J. Yan, 'Modelling and Simulation of an Adaptive Neuro-fuzzy Inference System (ANFIS) for Mobile Learning', IEEE Transactions on Learning Technologies, vol.5, no.3, pp. 226-237, 2010.

14. A. Al-Hmouz, A, J. Shen, J. Yan and R. Al-Hmouz, 'Enhanced Learner Model for Adaptive Mobile Learning', The 12th International Conference on Information Integration and Webbased Applications and Service, Paris, France, November 2010.

15. J. Kay, P. Reimann, E. Diebold and B. Kummerfeld, 'MOOCs: So Many Learners, So Much Potential', IEEE Intelligent Systems, vo. 28, no.3, pp.70-77, 2013.

16. A. Y. Kolb and A. D. Kolb, 'Learning styles and learning spaces: Enhancing experiential learning in higher education'. Academy of Management Learning and Education. vol.4, no.2, pp193-212, 2005.

17. D.C.Bui and J. Myerson, 'The Role of Working Memory Abilities in Lecture Note-taking', Learning and Individual Differences, vol.33, pp.12-22, 2014.

18. R.A.W. Tortorella and S. Graf, 'Personalised Mobile Learning via an Adaptive Engine', the 12th IEEE International Conference on Advanced Learning Technologies, Roma, July 2012.

19. C. M. Christensen, S. Aaron and W. Clark, 'Disruption in Education', The Internet and the University, pp.19-44. 2003.

20. S. Mark, R. Williams, J. Mackness, 'Blogs and Forums as Communication and Learning Tools in a MOOC', the 7th International Conference on Networked Learning, Aalborg, Denmark, May 2010.

21. C. Romero and S. Ventura, 'Educational Data Mining: a Review of the State-of-the-Art', IEEE Transactions on Systems, Man, and Cybernetics-Part C: Applications and Reviews, vol.40, no. 6, pp. 601-618, 2010. 